Effects of an i nhi bi tor of

3- hydr oxy- 3- net hyl gl ut aryl coenzyme a reduct ase on serum I i popr ot ei ns and ubi qui none- 10 l evel s in pati ent s wi th fami i al hyper chol est er ol em a

\begin{tabular}{|c|c|}
\hline 著者 & $\begin{array}{l}\text { Mabuchi Hi roshi, Haba Toshi hi ro, Tat ami Ryozo, } \\
\text { M yamot o Susumi, Sakai Yasuyuki, Wakasugi } \\
\text { Takanobu, Wat anabe Aki ra, Koi zum Junj i, } \\
\text { Takeda Ryoyu }\end{array}$ \\
\hline $\begin{array}{l}\text { jour nal or } \\
\text { publ i cat } i \text { on } t i t l e\end{array}$ & New Engl and Jour nal of Medi ci ne \\
\hline vol une & 305 \\
\hline nunber & 9 \\
\hline page $r$ ange & 478.482 \\
\hline year & 1981-01- 01 \\
\hline URL & ht t p: //hdl . handl e. net /2297/9918 \\
\hline
\end{tabular}




\title{
EFFECTS OF AN INHIBITOR OF 3-HYDROXY-3-METHYLGLUTARYL COENZYME A REDUCTASE ON SERUM LIPOPROTEINS AND UBIQUINONE-10 LEVELS IN PATIENTS WITH FAMILIAL HYPERCHOLESTEROLEMIA
}

\author{
Hiroshi Mabuchi, M.D., Toshihiro Haba, M.D., Ryzo Tatami, M.D., Susumu Miyamoto, M.D., \\ Yasuyuki Sakai, M.D., Takanobu Wakasugi, M.D., Akira Watanabe, M.D., Junji Koizumi, M.D., \\ and Ryoyu Takeda, M.D.
}

\begin{abstract}
We studied the effects of ML-236B, a competitive inhibitor of 3-hydroxy-3-methylglutaryl coenzyme $A$ (HMG-CoA) reductase, on serum levels of lipoproteins and ubiquinone-10 in seven heterozygous patients with familial hypercholesterolemia. ML-236B was given at doses of 30 to $60 \mathrm{mg}$ per day for 24 weeks. Serum cholesterol decreased from $390 \pm 9$ to $303 \pm 8 \mathrm{mg}$ per deciliter $(10.1 \pm 0.2$ to $7.88 \pm 0.2 \mathrm{mmol}$ per liter, mean \pm S.E.M.; $P<0.001$ ), and serum triglyceride decreased from $137 \pm 18$ to $87 \pm 9 \mathrm{mg}$ per deciliter $(1.55 \pm 0.20$ to $0.98 \pm 0.1 \mathrm{mmol}$ per liter; $P<0.05)$. Intermediate-density-lipoprotein (IDL) cholesterol, IDL triglyceride, low-density-lipoprotein (LDL) choles-
\end{abstract}

FAMILIAL hypercholesterolemia is a disease char1 acterized by elevated levels of low-density-lipoprotein (LDL) cholesterol, tendon xanthomas, and premature atherosclerosis. ${ }^{1}$ Recently, Goldstein and Brown demonstrated a complete or partial defect of the LDL receptor on the cell membranes of cultured skin fibroblasts from patients with familial hypercholesterolemia. ${ }^{2,3}$ The inability to bind LDL is associated with a consequent loss of feedback regulation of the rate-limiting enzyme of cholesterol biosynthesis, 3-hydroxy-3-methylglutaryl coenzyme A (HMG-CoA) reductase. This failure of autoregulation of cholesterol synthesis and the decreased receptor-mediated catabolism of LDL are thought to produce hypercholesterolemia in this disease. ${ }^{1,4}$ Thus, promoting receptor-mediated LDL catabolism and suppressing cholesterol synthesis by inhibiting HMG$\mathrm{CoA}$ reductase are theoretical means of therapy for familial hypercholesterolemia. ${ }^{1,4}$ The fungal metabolite ML-236B (compactin), discovered by Endo et al., is a potent inhibitor of HMG-CoA reductase both in vitro and in vivo. ${ }^{5-8}$

Mevalonate, which is formed by HMG-CoA reductase, is essential for several isoprenoid compounds as well as for cholesterol (Fig. 1). ${ }^{9}$ One of these nonsterol isoprenoid compounds is the polyisoprene side chain of ubiquinone (coenzyme $Q$ ), which is believed to be an important component of the electron-transfer system for coupled oxidative phosphorylation in the inner membranes of mitochondria. ${ }^{10}$ Thus, an inhibitor of HMG-CoA reductase may reduce both sterol and nonsterol products of mevalonate. We studied the effects of ML-236B on serum levels of lipoproteins and ubiquinone- 10 in patients with familial hypercholesterolemia.

From the Second Department of Internal Medicine, Kanazawa University School of Medicine, Takara-machi 13-1, Kanazawa, Ishikawa 920, Japan, where reprint requests should be addressed to Dr. Mabuchi. terol, and $L D L$ triglyceride decreased significantly $(P<0.01, P<0.02, P<0.001$, and $P<0.001$, respectively). However, there were no significant changes in very-low-density-lipoprotein (VLDL) cholesterol and triglyceride or high-density-lipoprotein (HDL) cholesterol. Serum ubiquinone-10 levels did not change, and LDL levels of ubiquinone-10 decreased by 50 per cent, from $0.39 \pm 0.07$ to $0.20 \pm 0.01 \mu \mathrm{g}$ per milliliter $(P<0.05)$. No adverse effects were observed. We conclude that ML-236B is effective in lowering serum cholesterol without lowering serum ubiquinone-10 in heterozygous patients with familial hypercholesterolemia. ( $\mathrm{N}$ Engl J Med. 1981; 305:478-82.)

\section{Methods}

The clinical data on seven heterozygous patients are summarized in Table 1. Patients 2, 3, and 4 are a brother and two sisters, and Patient 1 is their mother. Six of the seven patients (all but Patient 2) had both hypercholesterolemia and Achilles-tendon xanthomas. Achilles-tendon xanthomas were diagnosed by radiographic measurement of the thickness of the tendon. "None of the patients had clinical or laboratory evidence of cardiovascular, renal, hepatic, or endocrine disorders.

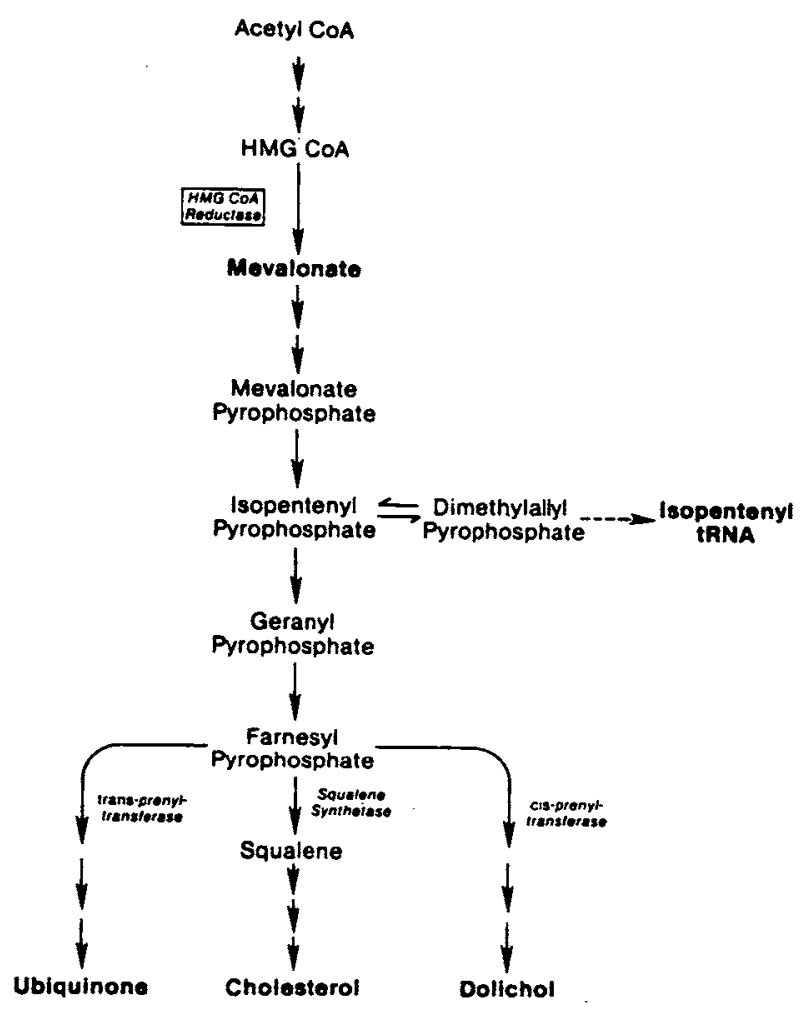

Figure 1. The Branched Pathway of Mevalonate Metabolism (Reproduced from Brown and Goldstein ${ }^{9}$ with the Permission of the Publisher). 


\begin{tabular}{ccccccc} 
No. & & & & & $\begin{array}{c}\text { TENDON } \\
\text { THICKNESS } \dagger\end{array}$ & ML-236B \\
& YR & & MG/DL & MG/DL & MM & MG/DAY \\
1 & 71 & F & 389 & 104 & 14.0 & 30 \\
2 & 45 & F & 378 & 116 & 6.5 & 30 \\
3 & 43 & F & 367 & 121 & 9.0 & 30 \\
4 & 39 & M & 406 & 219 & 16.0 & 30 \\
5 & 43 & M & 386 & 184 & 16.0 & 30 \\
6 & 43 & F & 434 & 139 & 17.0 & 60 \\
7 & 30 & F & 373 & 79 & 12.0 & 60 \\
Mean & 44 & & 390 & 137 & 12.9 & 38 \\
\hline
\end{tabular}

*To convert cholesterol and triglyceride values to millimoles per liter, multiply by 0.026 and 0.01129 , respectively.

$\nmid$ Normal value in Japanese subjects, $6.3 \pm 0.2 \mathrm{~mm}$ (mean \pm S.E.M.).

ML-236B was given three times daily for 24 weeks in doses of 60 $\mathrm{mg}$ per day in Patients 6 and 7 and $30 \mathrm{mg}$ per day in the other five patients (Table 1). Treatment with other hypocholesterolemic drugs was discontinued at least four weeks before this study began. The patients were instructed not to change their dietary habits throughout the study.

Blood samples, obtained in the morning after a 12-hour overnight fast, were allowed to clot at room temperature. Lipoprotein fractions were separated by serial ultracentrifugation at different densities, essentially by the method of Havel et al., ${ }^{2}$ into very-lowdensity lipoprotein (VLDL; density <1.006), intermediate-density lipoprotein (IDL; density, 1.006 to 1.019), LDL (density, 1.019 to 1.063), and high-density lipoprotein (HDL; density $>1.063$ ). Cholesterol and triglyceride levels were determined by the enzymatic method ${ }^{13}$ and Fletcher's method, ${ }^{14}$ respectively, in whole serum and in lipoprotein fractions. Serum samples for the determination of ubiquinone- 10 levels were kept at $-20^{\circ} \mathrm{C}$ and measured at a later time. Serum and LDL levels of ubiquinone-10 were measured with a high-speed liquid-chromatograph, JASCO FLC 350, equipped with an ultraviolet detector (275 nm), JASCO UVIDEC 100-II. ${ }^{15}$ Statistical calculation was performed with Student's paired t-test.

\section{Results}

All the patients had significant decreases in serum cholesterol levels without subsequent increases throughout the treatment period (Fig. 2). The mean serum cholesterol level ( \pm S.E.M.) decreased significantly from $390 \pm 9$ to $303 \pm 8 \mathrm{mg}$ per deciliter $(10.1 \pm 0.2$ to $7.88 \pm 0.2 \mathrm{mmol}$ per liter $)$ - a 22 per cent reduction $(\mathrm{P}<0.001)$ (Table 2$)$. The mean serum triglyceride level also decreased from $137 \pm 18$ to $87 \pm 9$ $\mathrm{mg}$ per deciliter $(1.55 \pm 0.20$ to $0.98 \pm 0.1 \mathrm{mmol}$ per liter) after 24 weeks $(P<0.05)$ (Table 2). Four weeks after the cessation of treatment, serum cholesterol and triglyceride returned to pretreatment levels (Fig. 2, Table 2).

VLDL cholesterol and triglyceride decreased, but not significantly (Table 2). IDL cholesterol, IDL triglyceride, LDL cholesterol, and LDL triglyceride decreased significantly $(P<0.01, P<0.02, P<0.001$, and $\mathrm{P}<0.001$, respectively) (Fig. 3 , Table 2 ). LDL cholesterol decreased by 29 per cent, from $299 \pm 9$ to $211 \pm 11 \mathrm{mg}$ per deciliter $(7.77 \pm 0.2$ to $5.49 \pm 0.29$ terol did not change significantly (Fig. 3, lable 2). After the cessation of treatment, LDL cholesterol increased from $211 \pm 11$ to $278 \pm 12 \mathrm{mg}$ per deciliter $(5.49 \pm 0.29$ to $7.23 \pm 0.31 \mathrm{mmol}$ per liter; $\mathrm{P}<0.01)$ (Fig. 3, Table 2).

Serum ubiquinone-10 levels did not change appreciably, falling from $0.89 \pm 0.13$ to $0.82 \pm 0.14 \mu \mathrm{g}$ per milliliter (mean \pm S.E.M. in 35 normal controls, $0.90 \pm 0.03 \mu \mathrm{g}$ per milliliter). On the other hand, ubiquinone-10 levels in the LDL fraction decreased significantly from $0.39 \pm 0.07$ to $0.20 \pm 0.01 \mu \mathrm{g}$ per milliliter - a change of 50 per cent $(P<0.05)$ (Table 3 ).

No changes in xanthomas were observed during this treatment period. No side effects, such as gastrointestinal, hematologic, neurologic, or other biochemical abnormalities, were observed in the patients (Table 4). However, serum uric acid decreased significantly $(\mathrm{P}<0.05)$, and plasma creatine phosphokinase increased, although not significantly.

\section{Discussion}

For the treatment of heterozygous familial hypercholesterolemia, cholestyramine, ${ }^{16-18}$ colestipol, ${ }^{17,19}$ niacin (nicotinic acid), ${ }^{20}$ clofibrate, ${ }^{20}$ probucol, ${ }^{21}$ and other drugs have been reported to be effective in lowering serum cholesterol levels. Among these drugs, the most effective and least toxic are bile acid sequestrants. However, bile acid sequestrants may produce gastrointestinal side effects, such as nausea, dysphagia, abdominal fullness, constipation, malabsorption of fat-soluble vitamins, and steatorrhea; moreover, these agents may cause increases in VLDL levels. ${ }^{22}$

According to the findings of Goldstein and Brown, familial hypercholesterolemia is a disorder resulting from decreased LDL catabolism by the receptor route
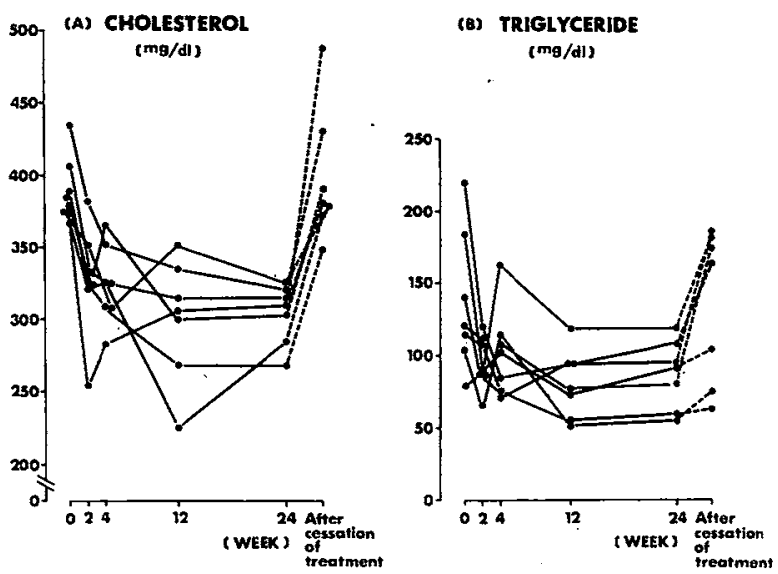

Figure 2. Effects of ML-236B on Serum Cholesterol (Panel A) and Triglyceride (Panel B) Levels in Heterozygous Patients with Familial Hypercholesterolemia.

To convert cholesterol and triglyceride values to millimoles per liter, multiply by 0.026 and 0.01129 , respectively. 
Table 2. Serum and Lipoprotein Cholesterol and Triglyceride Levels in Seven Heterozygous Patients with Familial Hypercholesterolemia before and after Treatment with ML-236B for 24 Weeks and after Discontinuation of Treatment.

\begin{tabular}{|c|c|c|c|c|c|c|}
\hline \multirow[t]{2}{*}{ LEVEL * } & \multirow{2}{*}{$\begin{array}{c}\text { BEFORE } \\
\text { TREATMENT } \\
\text { (A) }\end{array}$} & \multirow{2}{*}{$\begin{array}{c}\text { After } \\
\text { TREATMENT } \\
\text { (B) }\end{array}$} & \multirow{2}{*}{$\begin{array}{c}\text { AFTER } \\
\text { DisCON- } \\
\text { TINUATION } \\
\text { (C) }\end{array}$} & \multicolumn{3}{|c|}{ P V alue $f$} \\
\hline & & & & A vs. B & B vs. C & A vs. C \\
\hline & & $m g / d l$ & & & & \\
\hline \multicolumn{7}{|l|}{ Cholesterol } \\
\hline Whole serum & $390 \pm 9$ & $303 \pm 8$ & $399 \pm 17$ & $<0.001$ & $<0.001$ & NS \\
\hline VLDL & $18 \pm 4$ & $10 \pm 2$ & $19 \pm 6$ & NS & NS & NS \\
\hline IDL & $20 \pm 4$ & $8 \pm 1$ & $12 \pm 2$ & $<0.01$ & NS & NS \\
\hline LDL & $299 \pm 9$ & $211 \pm 11$ & $278 \pm 12$ & $<0.001$ & $<0.01$ & NS \\
\hline HDL & $55 \pm 5$ & $57 \pm 5$ & $50 \pm 5$ & NS & NS & NS \\
\hline \multicolumn{7}{|l|}{ Triglyceride } \\
\hline Whole serum & $137 \pm 18$ & $87 \pm 9$ & $137 \pm 21$ & $<0.05$ & $<0.05$ & NS \\
\hline VLDL & $43 \pm 13$ & $24 \pm 8$ & $25 \pm 11$ & NS & NS & NS \\
\hline IDL & $16 \pm 3$ & $8 \pm 1$ & $10 \pm 2$ & $<0.02$ & NS & NS \\
\hline LDL & $58 \pm 4$ & $28 \pm 3$ & $33 \pm 4$ & $<0.001$ & NS & $<0.01$ \\
\hline HDL & $18 \pm 1$ & $14 \pm 1$ & $25 \pm 6$ & $<0.02$ & NS & NS \\
\hline
\end{tabular}

To convert cholesterol and triglyceride values to millimoles per liter, multiply by 0.026 and 0.01129 , respectively. Figures are means \pm S.E.M. VLDL denotes very-low density lipoprotein, IDL intermediate-density lipoprotein, LDL low-density lipoprotein, and HDL high-density lipoprotein.

tObtained with Student's paired t-test. NS denotes not significant.

and from loss of feedback regulation of cholesterol synthesis. ${ }^{2}$ Thus, theoretical therapies should increase LDL catabolism or suppress cholesterol synthesis. ${ }^{1,4}$ Cholestyramine promotes LDL catabolism through its specific physiologic clearance pathway. ${ }^{23}$ No other drugs have been known to promote LDL-receptor activities in human beings. Oxygenated sterols, such as 7-ketosterol, 25-hydroxycholesterol, and others, have been known to inhibit cholesterol synthesis. ${ }^{24}$

Recently, Endo et al. isolated a new HMG-CoA reductase inhibitor (ML-236B) from the cultured broth of the mold Penicillium citrinum. ${ }^{5-8}$ This drug inhibits sterol synthesis from $\left[{ }^{14} \mathrm{C}\right]$ acetate in the cell-free system and in cultured cells, and its mode of action in the inhibition of the reductase is competitive with respect to the substrate, giving an inhibitor constant $\left(\mathrm{K}_{\mathrm{i}}\right)$ of approximately $1 \mathrm{nM}^{25,26}$ The inhibition of sterol synthesis caused by this drug is readily reversible. In vivo, ML-236B is effective in lowering plasma cholesterol levels in dogs, ${ }^{7}$ monkeys, ${ }^{8}$ hens, and rabbits, although it is ineffective in rats, mice, and hamsters. ${ }^{25}$ Recently, Yamamoto et al. reported that this drug was effective in reducing plasma cholesterol levels in human beings. ${ }^{27}$ They treated 11 patients with primary hypercholesterolemia (including heterozygous and homozygous patients with familial hypercholesterolemia) with doses of 50 to $150 \mathrm{mg}$ of ML-236B per day; they observed a 27 per cent reduction in serum cholesterol levels, which corresponded to the 22 per cent decrease in our study. However, they presented no data on lipoprotein lipid levels in their patients.
Cholesterol is essential for cell growth and steroidhormone synthesis. Sterol synthesis in various tissues, including the liver, kidney, lung, spleen, ileum, testis, adrenal gland, prostate, skin, muscle, and aorta, is suppressed by ML-236B. However, no severe adverse effects, such as hematologic, neurologic, endocrinologic, gastrointestinal, or hepatic abnormalities, have been reported. ${ }^{27}$ Yamamoto et al. have reported that a homozygous patient receiving $500 \mathrm{mg}$ per day had elevations in serum creatine phosphokinase, aspartate aminotransferase, and alanine aminotransferase, and that these side effects disappeared within two weeks after withdrawal of the drug. ${ }^{27}$ Several hypolipidemic drugs have been shown to reduce $^{28}$ or increase ${ }^{29}$ serum uric acid levels. ML-236B produced a slight but significant depression in serum uric acid, but the mechanism and the clinical importance of the decrement are unknown.

Fatty acid synthesis from $\left[{ }^{14} \mathrm{C}\right]$ acetate in human fibroblasts was found not to be affected by ML-236B at concentrations up to $5 \mu \mathrm{g}$ per milliliter. ${ }^{30}$ However, serum triglyceride levels in the heterozygotes decreased significantly in this study. This decrement in

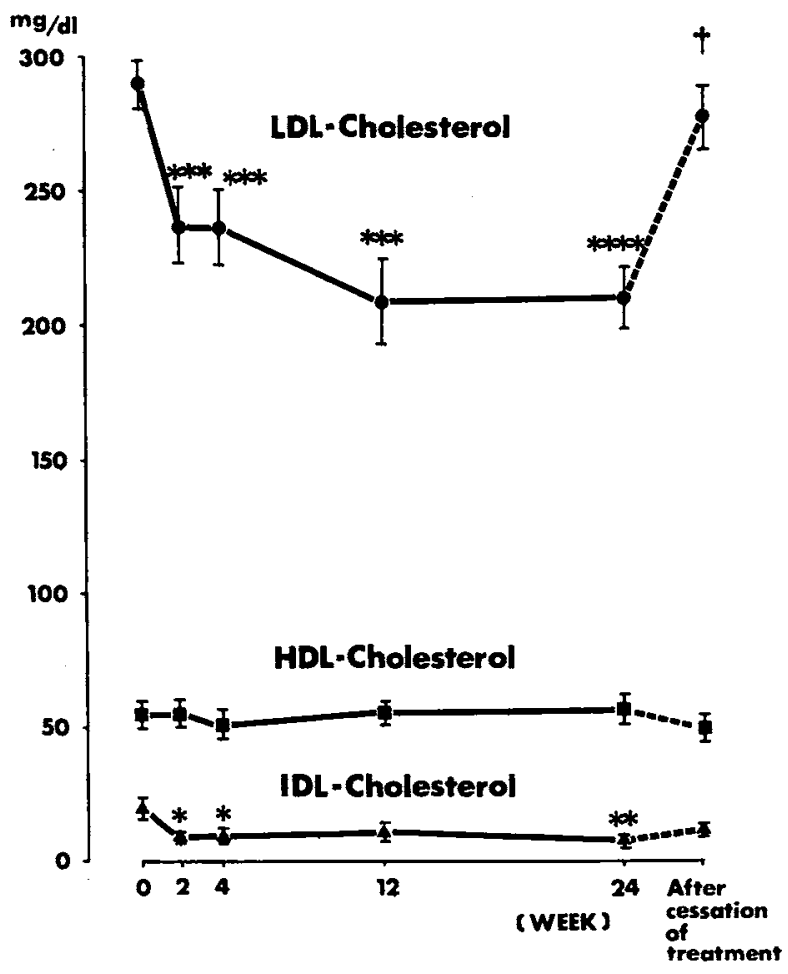

Figure 3. Effects of ML-236B on Intermediate-Density-Lipoprotein (IDL), Low-Density-Lipoprotein (LDL), and High-Density-Lipoprotein (HDL) Cholesterol Levels in Heterozygous Patients with Familial Hypercholesterolemia.

Data are means \pm S.E.M. To convert cholesterol and triglyceride values to millimoles per liter, multiply by 0.026 and 0.01129 , respectively. Asterisks $\left({ }^{*}\right)$ and dagger $(\dagger)$ denote $P$ values, obtained with Student's paired t-test: before treatment versus after treatment, ${ }^{*} P<0.05, * * P<0.02$, *** $P<0.01$, and $* * * * P<0.001$; after treatment versus after cessation of treatment, $+P<0.01$. 
1de and cholesterol trom VLUL coincided with the diurnal rhythm of hepatic HMG-CoA reductase activity. ${ }^{31}$ Although it has been suggested that LDL is secreted directly into plasma in patients with familial hypercholesterolemia ${ }^{32}$ virtually all LDL is derived from the metabolism of VLDL and its remnant, IDL. ${ }^{33}$ Thus, decreased VLDL production after suppression of cholesterol synthesis will decrease the IDL and LDL concentrations.

In dogs $^{7}$ and monkeys, ${ }^{8}$ both beta (LDL) and prebeta (VLDL) lipoproteins are decreased by ML236B, and in human beings, ${ }^{27}$ both VLDL and LDL cholesterol are decreased without concomitant changes in HDL cholesterol. In our study, the heterozygous patients had significant decreases in IDL cholesterol. This result suggests that ML-236B may be effective in lowering serum cholesterol levels in Type III hyperlipoproteinemia, in which IDL cholesterol is increased.' In heterozygotes with familial hyperlipoproteinemia, IDL and LDL cholesterols and triglycerides decreased without changes in the HDL-cholesterol level. Although the origin and metabolic fate of HDL cholesterol are not clearly known, ${ }^{34}$ this drug does not affect the level of HDL cholesterol. Since IDL and LDL cholesterols are atherogenic and HDL cholesterol is thought to be antiatherogenic, ${ }^{35} \mathrm{ML}-236 \mathrm{~B}$ is a reasonable hypocholesterolemic drug for the prevention of premature atherosclerosis.

In studies of the mechanism of the hypocholesterolemic actions of ML-236B and mevinolin, ${ }^{36}$ which is a structural analogue of ML-236B, Kovanen et al. demonstrated that mevinolin lowered LDL cholesterol in the dog by a dual mechanism: suppression of LDL synthesis and stimulation of the receptor-mediated catabolism of LDL in the liver. ${ }^{37}$ In cultured porcine hepatocytes, an increase in receptor-mediated

Table 3. Serum and Low-Density-Lipoprotein (LDL) Ubiquinone-10 Levels in Seven Heterozygous Patients with Familial Hypercholesterolemia before and after Treatment with ML-236B for 24 Weeks.

\begin{tabular}{|c|c|c|c|c|}
\hline \multirow{2}{*}{$\begin{array}{l}\text { Parient } \\
\text { No. }\end{array}$} & \multicolumn{2}{|c|}{ Serum Ubiquinone-10 } & \multicolumn{2}{|c|}{ LDL UBIQUINONE-10 } \\
\hline & $\begin{array}{c}\text { BEFORE } \\
\text { TREATMENT }\end{array}$ & $\begin{array}{c}\text { AFTER } \\
\text { TREATMENT }\end{array}$ & $\begin{array}{c}\text { BEFORE } \\
\text { TREATMENT }\end{array}$ & $\begin{array}{c}\text { APTER } \\
\text { TREATMENT }\end{array}$ \\
\hline & \multicolumn{2}{|c|}{$\mu g / m l$} & \multicolumn{2}{|c|}{$\mu g / m l$} \\
\hline 1 & 0.61 & - & 0.23 & 0.23 \\
\hline 2 & 0.83 & 1.02 & 0.36 & 0.22 \\
\hline 3 & 0.49 & 0.84 & 0.32 & 0.22 \\
\hline 4 & 1.17 & 1.15 & 0.67 & 0.19 \\
\hline 5 & 0.94 & - & 0.51 & 0.19 \\
\hline 6 & 1.31 & 0.80 & - & 0.14 \\
\hline 7 & - & 0.31 & 0.23 & 0.20 \\
\hline $\begin{array}{l}\text { Mean } \\
\quad \pm \text { S.E.M. }\end{array}$ & $0.89 \pm 0.13$ & $0.82 \pm 0.14$ & $0.39 \pm 0.07$ & $0.20 \pm 0.01$ \\
\hline
\end{tabular}

\begin{tabular}{lcc}
\hline \hline & BEFORE \\
VARIABLE * & $\begin{array}{c}\text { AFTER } \\
\text { TREATMENT }\end{array}$ & TREATMENT \\
Body weight (kg) & $57.2 \pm 5.8$ & $57.3 \pm 5.9$ \\
Blood pressure & $129 \pm 6$ & $118 \pm 6$ \\
$\quad$ Systolic (mm Hg) & $78 \pm 4$ & $72 \pm 4$ \\
Diastolic (mm Hg) & $464 \pm 18$ & $474 \pm 9$ \\
Red cells $\left(\times 10^{-4} / \mathrm{mm}^{3}\right.$ ) & $13.6 \pm 0.6$ & $13.7 \pm 0.4$ \\
Hemoglobin (g/dl) & $41 \pm 2$ & $41 \pm 1$ \\
Hematocrit (\%) & $71 \pm 3$ & $80 \pm 8$ \\
White cells ( $\times 10^{-2} / \mathrm{mm}^{3}$ ) & $7.4 \pm 0.1$ & $7.6 \pm 0.2$ \\
Serum protein (g/dl) & $1.6 \pm 0.1$ & $1.6 \pm 0.1$ \\
Albumin/globulin ratio & $22 \pm 3$ & $24 \pm 3$ \\
Serum aspartate aminotransferase (IU/liter) & $19 \pm 6$ & $19 \pm 8$ \\
Serum alanine aminotransferase (IU/liter) & $314 \pm 22$ & $303 \pm 21$ \\
Serum lactic dehydrogenase (IU/liter) & $64 \pm 8$ & $87 \pm 21$ \\
Serum creatine phosphokinase (IU/liter) & $204 \pm 41$ & $189 \pm 24$ \\
Alkaline phosphatase (IU/liter) & $5.5 \pm 0.5$ & $4.6 \pm 0.4$ \\
Uric acid (mg/d) $\dagger$ & $14 \pm 1$ & $13 \pm 1$ \\
Urea nitrogen (mg/dl) & $0.78 \pm 0.05$ & $0.76 \pm 0.05$ \\
Creatinine (mg/dl) & $85 \pm 4$ & $80 \pm 5$ \\
Fasting blood glucose (mg/dl) & $144 \pm 2$ & $143 \pm 1$ \\
Sodium (mmol/liter) & $4.1 \pm 0.2$ & $4.3 \pm 0.2$ \\
Potassium (mmol/liter) & $107 \pm 2$ & $106 \pm 1$ \\
Chloride (mmol/liter) & & \\
\hline
\end{tabular}

* To convert values for uric acid, urea nitrogen, and fasting blood glucose to millimoles per liter, multiply by $0.06,0.357$, and 0.0555 , respectively. To convert creatinine values to micromoles per liter, multiply by 88.4 .

$\dagger P$ of difference $<0.05$ by Student's paired $t$-test. All other differences were not significant.

degradation of LDL was also demonstrated after 18 hours of incubation with ML-236B, ${ }^{38}$ whereas in cultured human fibroblasts, ML-236B had no effects on the receptor-mediated uptake and degradation of [125I] LDL. ${ }^{26,39}$

Recently, new insights into the branched pathway of mevalonate metabolism have been elucidated in mammalian cells. ${ }^{9}$ In fibroblasts and smooth-muscle cells, radiolabeled mevalonate is converted into four end products that are essential for cell growth: cholesterol, dolichol, ubiquinone, and isopentenyl transfer RNA (Fig. 1). The length of the side chain of ubiquinone in these cells reaches 10 isoprene units (ubiquinone-10). Cholesterol and ubiquinone are thus synthesized through a common biosynthetic pathway involving mevalonate. ${ }^{40} \mathrm{It}$ is reasonable to assume that anything that would interfere with the supply of mevalonate would greatly affect the rate and extent of ubiquinone biosynthesis. Faust et al. ${ }^{40}$ and Nambudiri et al. ${ }^{41}$ have shown that the level of HMG-CoA reductase activity has a role in determining the rate of ubiquinone synthesis in cultured human fibroblasts. ML-236B is a potent inhibitor of HMG-CoA reductase and has a cholesterol-lowering effect in vitro and in vivo. However, in our study there was no decrement in the serum levels of ubiquinone-10, although 
the LDL compartment of ubiquinone-10 decreased significantly. When HMG-CoA reductase is partially suppressed by ML-236B as well as LDL, cells must have some way of diverting the small amounts of synthesized mevalonate preferentially into the crucial nonsterol products (e.g., ubiquinone). ${ }^{9}$ Thus, in the heterozygous patients in whom cholesterol synthesis was partially inhibited by ML-236B, serum ubiquinone-10 levels remained within the normal ranges. Ubiquinone-10 is a lipid-soluble substance that is mainly carried by lipoproteins. Therefore, it seems that the reduction in LDL as a carrier of ubiquinone10 was followed by the reduction in LDL levels of ubiquinone-10.

Thus, when one uses drugs that decrease serum cholesterol by inhibiting HMG-CoA reductase, attention must be paid to the nonsterol isoprenoid products of mevalonate. However, ML-236B is effective in the treatment of heterozygous familial hypercholesterolemia without changing the serum levels of ubiquinone-10.

We are indebted to the Sankyo Company, Tokyo, for providing the ML-236B used in this study; to the Eisai Company, Tokyo, for measuring ubiquinone-10; and to Dr. Robert $\mathrm{H}$. Knopp for his critical review.

\section{REFERENCES}

1. Fredrickson DS, Goldstein JL, Brown MS. The familial hyperlipoproteinemias. In: Stanbury JB, Wyngaarden JB, Fredrickson DS, eds. The metabolic basis of inherited disease. New York: McGraw-Hill, 1978:604-55.

2. Goldstein JL, Brown MS. The low-density lipoprotein pathway and its relation to atherosclerosis. Annu Rev Biochem. 1977; 46:897-930.

3. Idem. The LDL receptor locus and the genetics of familial hypercholesterolemia. Annu Rev Genet. 1979; 13:259-89.

4. Idem. Familial hypercholesterolemia: a genetic regulatory defect in cholesterol metabolism. Am J Med. 1975; 58:147-50.

5. Endo A, Kuroda M, Tsujita Y. ML-236A, ML-236B, and ML-236C, new inhibitors of cholesterogenesis produced by Penicillium citrinum. J Antibiot (Tokyo). 1976; 29:1346-8.

6. Endo A, Tsujita Y, Kuroda M, Tanzawa K. Inhibition of cholesterol synthesis in vitro and in vivo by ML-236A and ML-236B, competitive inhibitors of 3-hydroxy-3-methylglutaryl-coenzyme A reductase. Eur J Biochem. 1977; 77:31-6.

7. Tsujita $Y$, Kuroda M, Tanzawa K, Kitano N, Endo A. Hypolipidemic effects in dogs of ML-236B, a competitive inhibitor of 3-hydroxy-3methylglutaryl coenzyme A reductase. Atherosclerosis. 1979; 32:307-13.

8. Kuroda M, Tsujita Y, Tanzawa K, Endo A. Hypolipidemic effects in monkeys of ML-236B, a competitive inhibitor of 3-hydroxy-3-methylglutaryl coenzyme A reductase. Lipids. 1979; 14:585-9.

9. Brown MS, Goldstein JL. Multivalent feedback regulation of HMG CoA reductase, a control mechanism coordinating isoprenoid synthesis and cell growth. J Lipid Res. 1980; 21:505-17.

10. DePierre JW, Ernster L. Enzyme topology of intracellular membranes. Annu Rev Biochem. 1977; 46:201-62.

11. Mabuchi $H$, Ito $S$, Haba $T$, et al. Discrimination of familial hypercholesterolemia and secondary hypercholesterolemia by Achilles' tendon thickness. Atherosclerosis. 1977; 28:61-8.

12. Havel RJ, Eder HA, Bragdon JH. The distribution and chemical composition of ultracentrifugally separated lipoproteins in human serum. J Clin Invest. 1955; 34:1345-53.

13. Allain CC, Poon LS, Chan CSG, Richmond W, Fu PC. Enzymatic determination of total serum cholesterol. Clin Chem. 1974; 20:470-5.

14. Fletcher MJ. A colorimetric method for estimating serum triglycerides. Clin Chim Acta. 1968; 22:393-7.

15. Abe K, Ishibashi K, Ohmae M, Kawabe K, Katsui G. Determination of ubiquinone in serum and liver by high-speed liquid chromatography. J Nutr Sci Vitaminol (Tokyo). 1978; 24:555-67.

16. Levy RI, Fredrickson DS, Stone NJ, et al. Cholestyramine in type II hyperlipoproteinemia: a double-blind trial. Ann Intern Med. 1973; 79:51-8.

17. Glueck CJ, Ford S Jr, Scheel D, Steiner P. Colestipol and cholestyramine resin: comparative effects in familial type II hyperlipoproteinemia. JAMA. 1972; 222:676-81.

18. Hashim SA, Van Itallie TB. Cholestyramine resin therapy for hypercholesteremia. JAMA. 1965; 192:289-93.

19. Miettinen TA. Changes in cholesterol metabolism by colestipol hydrochloride in hypercholesterolemic patients. Eur J Clin Invest. 1974; 4:365-6. abstract.

20. The Coronary Drug Project Research Group. Clofibrate and niacin in coronary heart disease. JAMA. 1975; 231:360-81.

21. Miettinen TA. Mode of action of a new hypocholesteraemic drug (DH581) in familial hypercholesteraemia. Atherosclerosis. 1972; 15:163-76.

22. Miller NE, Nestel PJ. Differences among hyperlipoproteinaemic subjects in the response of lipoprotein lipids to resin therapy. Eur J Clin Invest. 1975; 5:241-7.

23. Shepherd J, Packard CJ, Bicker S, Lawrie TDV, Morgan HG. Cholestyramine promotes receptor-mediated low-density-lipoprotein catabolism. N Engl J Med. 1980; 302:1219-22.

24. Chen HW, Kandutsch AA, Waymouth $C$. Inhibition of cell growth by oxygenated derivatives of cholesterol. Nature. 1974; 251:419-21.

25. Endo A. Biological and biochemical aspects of ML-236B (compactin) and monacolin $\mathrm{K}$, specific competitive inhibitors of 3-hydroxy-3methylglutaryl coenzyme A reductase. In: Gotto AM, Smith LC, Allen B, eds. Atherosclerosis V. New York: Springer-Verlag, 1980:152-5.

26. Brown MS, Faust JR, Goldstein JL, Kaneko I, Endo A. Induction of 3-hydroxy-3-methylglutaryl coenzyme A reductase activity in human fibroblasts incubated with compactin (ML-236B), a competitive inhibitor of the reductase. J Biol Chem. 1978; 253:1121-8.

27. Yamamoto A, Sudo H, Endo A. Therapeutic effects of ML-236B in primary hypercholesterolemia. Atherosclerosis. 1980; 35:259-66.

28. Oliver MF. Reduction of serum-lipid and uric-acid levels by an orally active androsterone. Lancet. 1962; 1:1321-3.

29. Parsons WB Jr. Studies of nicotinic acid use in hypercholesteremia: changes in hepatic function, carbohydrate tolerance, and uric acid metabolism. Arch Intern Med. 1961; 107:653-67.

30. Kaneko I, Hazama-Shimada $Y$, Endo A. Inhibitory effects on lipid metabolism in cultured cells of ML-236B, a potent inhibitor of 3hydroxy-3-methylglutaryl-coenzyme-A reductase. Eur J Biochem. 1978; 87:313-21.

31. Goh EH, Heimburg M. Relationship between activity of hepatic 3-hydroxy-3-methylglutaryl-coenzyme $A$ reductase and secretion of verylow-density-lipoprotein cholesterol by the isolated perfused liver and in the intact rat. Biochem J. 1979; 184:1-6.

32. Thompson GR, Soutar AK, Myant NB. VLDL-independent synthesis of LDL-apo-B in familial hypercholesterolemia (FH). Circulation. 1976; 54: Suppl II:II-26. abstract.

33. Eisenberg S, Levy RI. Lipoprotein metabolism. Adv Lipid Res. 1975; 13:1-89.

34. Tall AR, Small DM. Plasma high-density lipoproteins. N Engl J Med. 1978; 299:1232-6.

35. Miller GJ, Miller NE. Plasma-high-density-lipoprotein concentration and development of ischaemic heart-disease. Lancet. 1975; 1:16-9.

36. . Alberts AW, Chen J, Kuron G, et al. Mevinolin: a highly potent competitive inhibitor of hydroxymethylglutaryl-coenzyme A reductase and a cholesterol-lowering agent. Proc Natl Acad Sci USA. 1980; 77:395761.

37. Kovanen PT, Bilheimer DW, Goldstein JL, Jaramillo JJ, Brown MS. Regulatory role for hepatic low density lipoprotein receptors in vivo in the dog. Proc. Natl Acad Sci USA. 1981; 78:1194-8.

38. Pangburn SH, Newton RS, Chang C-M, Weinstein DB, Steinberg D. Receptor-mediated catabolism of homologous low density lipoproteins in cultured pig hepatocytes. J Biol Chem. 1981; 256:3340-7.

39. Haba T, Mabuchi H, Yoshimura A, et al. Effects of ML-236B (compactin) on sterol synthesis and low density lipoprotein receptor activities in fibroblasts of patients with homozygous familial hypercholesterolemia. J Clin Invest. 1981; 67:1532-40.

40. Faust JR, Goldstein JL, Brown MS. Synthesis of ubiquinone and cholesterol in human fibroblasts: regulation of a branched pathway. Arch Biochem Biophys. 1979; 192:86-99.

41. Nambudiri AMD, Ranganathan S, Rudney H. The role of 3-hydroxy3-methylglutaryl coenzyme $A$ reductase activity in the regulation of ubiquinone synthesis in human fibroblasts. J Biol Chem. 1980; 255:5894-9. 